\title{
Recognition of caste and mating status maintains monogyny in the ant Aphaenogaster senilis
}

\author{
Camille Ruel • Abraham Hefetz • Xim Cerdá • \\ Raphaël Boulay
}

\begin{abstract}
In ants dispersing through colony fission, queens mate near their natal nest and found a new society with the help of workers. This allows potential future queens to challenge the mother queen's reproductive monopoly. Conflicts might be resolved if the mated queen signals her presence and the workers control the developmental fate of the diploid larvae (whether they develop to worker or queen). In this study we sought to determine whether, in the fissionperforming ant Aphaenogaster senilis, conflicts between queens for control of the colony are resolved by the resident queen signalling her mating status. Virgin queens were less effective than newly mated queens in inhibiting queen rearing. Moreover, potential challenger queens were recognized and heavily aggressed independent of mating status. Chemical analyses showed that mating status was associated with changes in cuticular hydrocarbon and poison gland composition, but not in Dufour's gland composition. Cuticular dimethylalkanes were identified as potential constituents that
\end{abstract}

\section{Ruel $\cdot$ X. Cerdá}

Estación Biológica de Doñana, Consejo Superior de Investigaciones Científicas, Avenida Américo Vespucio, s/n, 41092 Seville, Spain

\author{
A. Hefetz \\ Department of Zoology, Tel Aviv University, Ramat Aviv, \\ Tel Aviv 69978, Israel \\ R. Boulay \\ Departamento de Zoología, Universidad de Granada, \\ Campus Fuente Nueva, \\ 18071 Granada, Spain \\ R. Boulay $(\bowtie)$ \\ Institut de Recherche sur la Biologie de l'Insecte, UMR CNRS \\ 7261, Université François Rabelais, 37200 Tours, France \\ e-mail: raphael.boulay@univ-tours.fr
}

signal both caste (present in queens only) and mating status (mated queens have higher amounts). We hypothesised that pheromone emission by virgin queens did not reach the threshold needed to fully inhibit larval development into queens but was sufficiently high to stimulate overt aggression by mated queens. These findings provide evidence for the complexity of chemical communication in social insects, in which a small number of signals may have a variety of effects, depending on the context.

Keywords Hymenoptera · Age · Queen pheromone · Cuticular hydrocarbons $\cdot$ Dufour's gland $\cdot$ Poison gland

\section{Introduction}

Ants present a classical model system in evolutionary biology due to their great diversity of social organisations (Bourke and Franks 1995; Crozier and Pamilo 1996; Hölldobler and Wilson 2009). In ancestral ants, queens formed their colonies alone (i.e. without the help of workers; independent colony founding) and also produced all the offspring (Cronin et al. 2013). High genetic relatedness among colony members probably favoured the evolution of altruistic interactions through kin selection (Hamilton 1964). Although independent colony founding is still very common in extant ant species, many species have evolved a dependent mode of colony founding that reduces mortality associated with the queen's solitary phase (Cronin et al. 2013). For example, young queens can be integrated into an already founded nest, which increases the number of breeders and reduces intra-colony relatedness (Keller 1991; Liautard and Keller 2001; Pamilo 1991). Alternatively, a queen may leave her natal nest with a worker force to found a new colony in the vicinity of the mother colony. This colony fission strategy guarantees both high foundation success and monogyny. In ants, colony fission occurs, for example, in army ants (Godwald 1995), in desert ants Cataglyphis 
floricola (Amor et al. 2011) and Cataglyphis cursor (Chéron et al. 2011) and in the gipsy ant Aphaenogaster senilis (Boulay et al. 2010; Galarza et al. 2012). Several species of bees, including the honeybee Apis mellifera (Seeley 1985), and the Polybiine wasps (Ross and Mathews 1991) also disperse through fission.

Apart from a few noticeable exceptions (e.g. Pearcy et al. 2004; Leniaud et al. 2012), the development of ant diploid larvae to either queen or worker is generally determined by environmental factors. Kin selection theory predicts that when larvae are totipotent up to a certain stage, they can obtain greater direct fitness by developing to queens rather than workers, since the former are more related to their own progeny than that of any other female nestmate (Bourke and Ratnieks 1999; Nonacs and Tobin 1992). The result of such selfish larvae is supernumerary new queens, which is disadvantageous to the adults, resident queens and workers alike. It is therefore predicted that either the resident queen or workers will evolve a means to regulate the number of new queens that develop in the colony. The conflict may be accentuated in monogynous fission-performing species since the production of only a few new queens is sufficient to guarantee the colony reproductive success (Pamilo 1991; Bourke and Ratnieks 1999; Wenseleers and Ratnieks 2004).

Overt conflicts between the newly emerged queens and the mother queen are also predicted in fission-performing ants because since the daughter queens mate near the natal nest, they may have the opportunity to usurp their mother queen position. Moreover, the new nest is generally established in the vicinity of the mother nest. Since the workers are sisters, they bear similar heritable nestmate recognition cues, and thus may not recognize each other as aliens (Ichinose et al. 2005). This provides an opportunity for colony merging and consequently overt conflict between queens. Mother queens should, therefore, be selected to be aggressive even towards their daughter queens as well as to trigger aggression by workers towards them.

In the monogynous ant $A$. senilis, both field and laboratory studies suggest the existence of a queen pheromone that inhibits the development of almost all diploid larvae into new queens (Boulay et al. 2007); although larvae are totipotent, only a limited number of queens develop and only when the mother queen disappears or just before the colony is ready to reproduce by fission (Boulay et al. 2009; Ruel et al. 2012). However, the mechanism by which such inhibition is achieved remains elusive. According to the "honest signalling" theory, the queen pheromone is predicted to reliably signal both her mating status and reproductive potential, and the brood and/or worker behavioural and physiological responses are expected to be proportional to the queen's quality (Hannonen et al. 2002; Kocher et al. 2009). The importance of signalling mating status in the competition between virgin and newly-mated queens is corroborated by several studies showing that important changes in pheromone composition accompany the post-mating physiological modifications (Hora et al. 2008; Kocher et al. 2008; Castella et al. 2009). In the present study, we investigated whether, in A. senilis, signalling of the mating status resolves or at least mitigates the conflicts over which queen will head the colony.

The chemistry of ant queen pheromones has been little studied and has focused to date mainly on cuticular hydrocarbons (HCs; review in Hefetz 2007). For example, 3,11 dimethylheptacosane mediates the recognition of egg-laying individuals in Pachycondyla inversa (D'Ettorre et al. 2004); 3-methylhentriacontane mediates the regulation of worker sterility in Lasius niger (Holman et al. 2010); and pentacosane elicits worker policing in queenright colonies of Aphaenogaster cockerelli (Smith et al. 2009). Although queen pheromones may have multiple origins (Vargo and Husley 2000), less attention has been given to the role of queen glandular secretions other than cuticular HCs in queen regulation of social behaviour. In the well-studied fire ant Solenopsis invicta, the poison gland is the source of a queen pheromone (Vander Meer et al. 1980; Vargo 1997) that was shown to trigger the elimination of untimely sexual larvae (Klobuchar and Deslippe 2002). Caste-specific secretion was also described in Dufour's gland in some ant species, e.g. A. senilis and A. cockerelli (Boulay et al. 2007; Smith et al. 2012).

Here we examined the effects of putative queen pheromones on larval development and worker behaviour, by comparing same-age newly mated queens and virgin queens. We first tested the hypothesis that a queen pheromone preventing the untimely development of larvae into queens is present in mated, but not in virgin, queens. We then determined whether the mother queen, her workers or both would be intolerant to any newly arriving queen irrespective of her mating status; or whether they would aggress mated queens and be more tolerant towards virgin queens. Finally, we explored the chemical differences between same-age newly-mated queens and virgin queens in cuticular HCs and Dufour's and the poison gland secretions in order to identify candidate chemicals acting as queen primer and releaser pheromones.

\section{Methods}

Colony collection and maintenance

Source colonies of $A$. senilis were collected in July 2011 from the Doñana National Park (south-western Spain). In the laboratory, they were housed in $\varnothing 2 \times 20 \mathrm{~cm}$ test tubes, the bottom filled with water and stoppered with a cotton plug. The tubes were kept in $28 \times 18 \times 11 \mathrm{~cm}$ Fluon-lined (to 
prevent the ants from escaping) containers that served as a foraging arena. Colonies were kept in darkness at $28^{\circ} \mathrm{C} \pm 1^{\circ}$ $\mathrm{C}$ and $50 \% \pm 10 \%$ humidity, and were fed with mealworms (Tenebrio molitor) and honey.

Production of virgin (VQ) and newly-mated (NMQ) queens under fenced field conditions

On August 8, 2011, 13 colonies containing abundant brood including totipotent 1 st instar larvae were each divided, depending on the initial colony size, into either two, three or four groups comprising at least 400 workers each, totalling 40 groups, 27 queenless (QL) and 13 queenright. The groups containing the mother queen (MQ) were kept in the laboratory for the following experiments. In order to generate virgin queens (VQ) and newly-mated queens (NMQ), the 27 QL groups (the daughter colonies) were housed in circular nest-boxes (ø10 cm and 14 or $27 \mathrm{~cm}$ high), halffilled with moist sand, and were returned to the Doñana National Park. These nest boxes were buried about $40 \mathrm{~cm}$ deep in the ground to protect the ants from extreme ground surface temperature $\left(>60{ }^{\circ} \mathrm{C}\right.$ at midday) and connected by $20 \mathrm{~cm}$ tubing to a $\varnothing 23 \times 24-\mathrm{cm}$ circular foraging arena placed on the ground surface. The colonies were provided with mealworms and biscuits every second week and kept under these conditions for almost two months to allow them to rear at least one new queen (Ruel, unpublished). As A. senilis queens have short wings, they could not fly out of the foraging arena for mating, and relied on males from surrounding wild colonies that could fly in and mate with them. To obtain NMQs, the foraging arenas of 19 daughter colonies were left open to allow such males to reach the newly emerged queens. To obtain same-age VQs, we covered the foraging arenas of eight colonies with a fine mesh to prevent males from entering (although these colonies produced males, $A$. senilis queens avoid mating with brothers (Boulay, unpublished)).

On September 29, all nests were brought to the laboratory and the queens' mating status was assessed by the absence of wings (verified a posteriori by examining the dissected spermatheca). Nine alate VQs and 13 wingless NMQs were found in 9 and 13 daughter colonies, respectively. The remaining seven daughter colonies either died or did not produce queens. As the development from 1st instar larvae to adulthood takes about one month (Ruel, unpublished data), we estimate that queen age was less than 20 days when returned to the lab.

Effect of queen mating status on the rearing of new queens

To determine whether mated queens, but not virgin ones, emit a pheromone that inhibits larval development into queens, five daughter colonies containing a VQ and eight colonies containing a NMQ were each divided into a QL and a QR group. Groups constructed from the same field colony were of equal size, but varied between 96 and 200 workers across different field colonies. Two additional VQ daughter colonies were used but were not divided due to insufficient worker numbers. Two additional QL groups were created from the largest VQ daughter colony as control. In total, we created 7 VQ groups, $8 \mathrm{NMQ}$ groups and 15 QL groups. All the brood present in these colonies was removed and replaced by 201 st instar larvae from their respective mother colonies to standardize queen production. All groups were placed separately in $ø 2 \times 20 \mathrm{~cm}$ test tubes containing a water reservoir at the bottom and connected to a $ø 10 \times 10 \mathrm{~cm}$ circular Fluon-lined box. The number of queen-developing pupae was counted three times a week for 40 days. These pupae were removed systematically so they were not counted twice. We also monitored, for each group, whether eggs were present on the 13th day of the experiment, which was previously shown to be the time frame for egg-laying by orphaned workers (Ruel et al. 2012).

\section{Are NMQs more aggressed than VQs?}

To determine whether workers and queens recognized daughter-queens' mating status, we examined the aggressive interactions between workers as well as MQs, and NMQs or VQs. In November 2011, we composed 10 daughter groups, five headed by a VQ and five by a NMQ. These groups were derived from six different source colonies (a-f; Table 1). Each group contained 150 sister workers (the time-frame of the experiment was too short to allow the NMQ offspring to develop to adulthood). We also created six MQ groups (a-f; Table 1) containing 150 workers that we marked with a dot of paint on the head or abdomen to identify their origin.

Bioassays were conducted by gently placing two groups in the same $31 \times 20 \times 6 \mathrm{~cm}$ Fluon-lined box, and observing whether aggression took place between the tested queens

Table 1 Repartition of the six different colonies (each represented by a letter from a to f) between the 15 aggression tests

\begin{tabular}{llll}
\hline $\begin{array}{l}\text { Mother } \\
\text { queen }\end{array}$ & $\begin{array}{l}\text { Virgin } \\
\text { queen }\end{array}$ & $\begin{array}{l}\text { Daughter newly } \\
\text { mated queen }\end{array}$ & $\begin{array}{l}\text { Alien newly } \\
\text { mated queen }\end{array}$ \\
\hline MQ a & VQ a & NMQ a & NMQ b \\
MQ b & VQ b & NMQ b & NMQ c \\
MQ c & VQ c & NMQ c & NMQ d \\
MQ d & VQ d & NMQ d & \\
MQ e & VQ e & & NMQ f \\
MQ f & & NMQ f & NMQ a \\
\hline
\end{tabular}

The tests were performed between a MQ group and a group with either a daughter VQ, a daughter NMQ or an alien NMQ 
and their respective workers. The assays were stopped after 30 min or when too many workers aggregated to form an aggressive mass around the queens. The MQ groups a-d were tested in succession against their respective daughter VQ group $(n=5)$, daughter NMQ group $(n=5)$, and against an unrelated NMQ group as a positive control $(n=5)$. The MQ group e was tested only against a VQ daughter group and a NMQ alien group, while the MQ group $f$ was tested against an NMQ daughter group and an NMQ alien group (Table 1). The order of the tests was random and only one test was conducted per group per day.

We recorded the time elapsed to first aggression between queens, and the number of worker aggressions towards the queens, every $3 \mathrm{~min}$ on a three-level scale: (a) opening the mandibles, (b) bending the abdomen, and (c) biting and pulling the appendages. For 10 out of the 15 aggression tests ( 3 between non-related, 7 between related workers), we also video-recorded (JVC Everio GZ-HD520) the encounters between workers from different groups, and workerworker aggressions were observed on a $\varnothing 9-\mathrm{cm}$ area during the first $3 \mathrm{~min}$.

Queen chemical profiles as a function of the mating status

The composition of the cuticular HCs, and Dufour's and poison gland secretions of seven VQs and 11 NMQs from the daughter colonies were compared. NMQs and VQs were collected one week after the bioassays, frozen at $-20^{\circ} \mathrm{C}$ and subsequently dissected to separate the thorax, Dufour's and poison glands. The degree of ovarian development, the presence of yellow bodies and a full spermatheca served to determine the queens' reproductive and mating status, respectively. Thoraces, Dufour's and poison glands were extracted in $50 \mu \mathrm{L}$ dichloromethane and stored at $-20{ }^{\circ} \mathrm{C}$ until chemical analyses. Samples were injected into a gas chromatograph (GC 2010 Shimadzu) equipped with a Flame Ionization Detector. For long-chain thoracic HCs oven temperature was programmed from $130{ }^{\circ} \mathrm{C}$ to $240{ }^{\circ} \mathrm{C}$ at $15^{\circ} \mathrm{C} \mathrm{min}{ }^{-1}$, then from $240{ }^{\circ} \mathrm{C}$ to $300{ }^{\circ} \mathrm{C}$ at $3{ }^{\circ} \mathrm{C} \mathrm{min}{ }^{-1}$. For glandular extracts, temperature was programmed from $60^{\circ} \mathrm{C}$ to $210^{\circ} \mathrm{C}$ at $5^{\circ} \mathrm{C} \mathrm{min}^{-1}$, then $210^{\circ} \mathrm{C}$ to $300{ }^{\circ} \mathrm{C}$ at $15^{\circ} \mathrm{C} \mathrm{min}^{-1}$. Twenty nanograms of eicosane were added to each sample as an internal standard. Peaks were verified by combined gas chromatography/mass spectrometry (AutoSpec Premier, Waters) using the above-mentioned chromatographic conditions.

Statistical analyses

All data were analysed using the R-package software v. 2.7.2 (R Core team, 2011). Three generalized linear mixed models (GLMM, lme4 package) were fitted to compare the probability and number of larvae developing into queens, and the probability of egg- laying between VQ, NMQ and QL groups. The response variables were the binary production of queens (binomial distribution), the number of queens produced (Poisson distribution) and the presence of eggs on the 13th day of the experiment (binomial distribution). Another GLMM was fitted to compare the probability of aggression when workers from different nests encountered each other. The response variable was the number of passive and aggressive interactions observed (binomial distribution). For all the models, the colony was included as a random factor. The significance of each factor level was assessed by contrast analysis. The latency to aggression, as well as its intensity, was compared according to the mating status of the queens using the Mann-Whitney test.

For the chemical data, we first compared both the total amount of secretions and that of the main chemical classes extracted from the queens' cuticle, Dufour's gland and poison gland as a function of the queens' mating status, using Mann-Whitney tests followed by the sequential Holm-Bonferroni correction for multiple comparisons. We therefore regrouped the chemical compounds by classes that composed more than $5 \%$ of the total. We then performed multivariate analyses on the relative proportions of a subset of 13, 11 and nine compounds (respectively for thoracic cuticular HCs, the Dufour's and the poison glands) that represented more than $2 \%, 1 \%$ and $0.4 \%$ of the total quantity in at least half of the samples. Prior to the analyses, we standardized the relative proportions by subtracting the mean proportion of a compound from each individual proportion and dividing the result by the standard deviation of the mean (Quinn and Keough 2002). Hierarchical cluster analyses by complete linkage method were performed in order to determine whether NMQs and VQs clustered in two different groups based on the proportion of the previously defined major compounds. The mean proportion of these compounds from 10 workers from foreign colonies was used as an out-group. The Bray-Curtis distance matrix was used to compare the chemical distances between NMQs and VQs (NMQ-VQ) and among NMQs or among VQs (NMQ-NMQ and VQ-VQ) by performing two permutation tests. Finally, principal component analyses were conducted in order to identify those variables that best separated between queens according to their mating status. All estimates were means $\pm \mathrm{SE}$.

\section{Results}

Effect of queen mating status on the rearing of new queens

Dissections confirmed that all alate individuals classified as VQs had empty spermatheca and undeveloped ovaries, whereas a full spermatheca, growing oocytes and yellow 
body were observed in all wingless individuals classified as NMQs. Thus, the presence of wings in queens born in the field is a good diagnostic of mating status.

Queen production was highest in QL groups ( $80 \%$ of the groups), lowest in the NMQ groups (none of the groups) and intermediate in the VQ groups ( $43 \%$ of the groups). The probability of producing at least one queen in the QL groups was higher than in the NMQ treatment (GLMM: $Z=2.148$, $P=0.032$ ). However, in VQ groups the probability of producing one queen did not differ significantly either from that of the QL $(Z=1.674, P=0.094)$, or that of the NMQ groups $(Z=-0.377, P=0.706)$.

The number of queens produced in the QL groups $(1.80 \pm$ $0.35)$ was significantly higher than in the NMQ groups $(0.00 \pm 0.00, Z=3.054, P=0.002$; Fig. 1$)$. The number of queens produced in the VQ groups $(0.71 \pm 0.36)$ was intermediate, and did not significantly differ from the QL treatment $(Z=1.898, P=0.058)$, or the NMQ treatment $(Z=-0.752, P=0.452)$.

On the 13th day, eggs were present in each of the $8 \mathrm{NMQ}$ groups, in three out of seven VQ groups (57\%) and in seven out of 15 QL groups (53\%). None of the pair-wise differences in the proportion of groups having eggs was significant (GLMM: NMQ vs VQ: $Z=-0.603, P=0.547$; NMQ vs QL: $Z=-0.653, P=0.514$; VQ vs $\mathrm{QL}: Z=0.037, P=0.97$ ). Although we did not count the number of eggs, they were clearly more abundant in the NMQ groups than in the other two groups (Ruel, personal observation). Queen dissection revealed that the eggs observed in the NMQ groups were

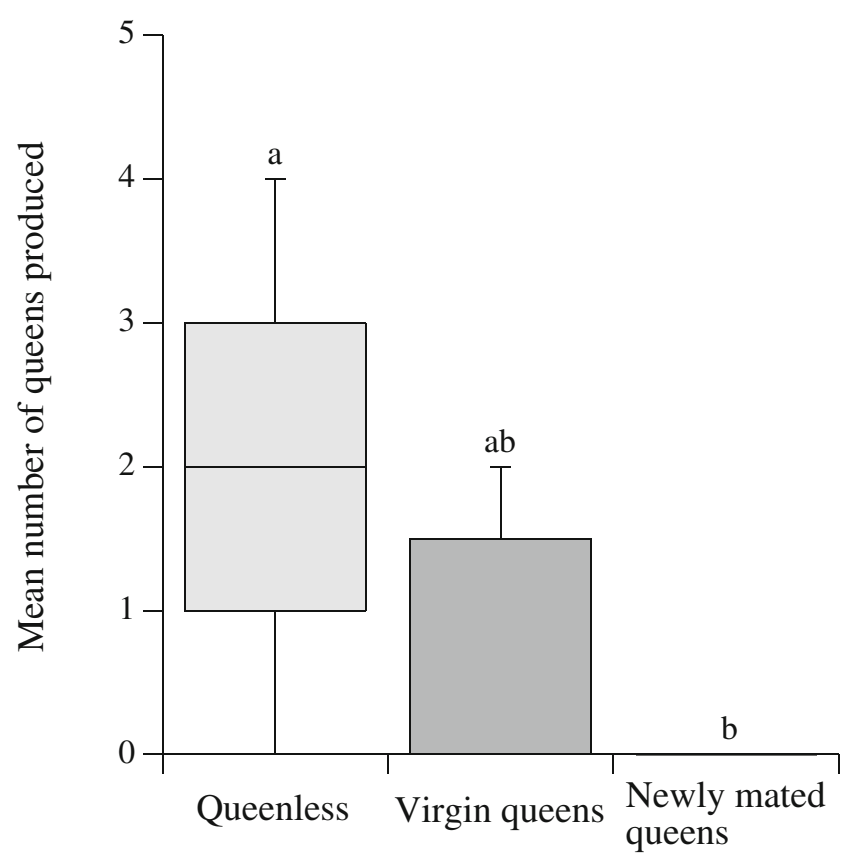

Fig. 1 Number of queens produced in the queenless, virgin queens and newly mated queens groups. Different letters denote significant differences most probably laid by the NMQs, judging from their ovarian status. Those observed in the VQ groups were worker-laid, since the VQs had undeveloped ovaries and no yellow bodies.

Are NMQs more aggressed than VQs?

Physical contact between queens was always followed by overt aggression (10 aggressions on 10 physical contacts). Queens bit each other and rubbed their abdomen onto their challenger's body. VQs were attacked by MQs in four out of five tests, while aggressions between NMQs and MQs were observed in 6 out of 10 tests (three for daughter and three for alien NMQs). None of the queens attacked workers but $83.3 \%$ of the queens (VQ, NMQ or MQ) are aggressed at least once by workers during the bioassay. The intensity of aggression by workers did not depend on queen mating status (Fig. 2; $U=13, N_{l}=5, N_{2}=5, P=1$ ). On 13 occasions, the workers aggressed both the opponent queen and their own queen (VQ, NMQ or MQ). However, workers were more aggressive towards the opponent than their own queen (9.2 \pm 1.9 vs $4.3 \pm 1.1 ; U=318.5, N_{I}=30, N_{2}=30, P=0.042$ ). Finally, workers from the MQ groups were equally aggressive towards daughter NMQs as towards unrelated NMQs (aggression index: $11.2 \pm 5$ vs $4.8 \pm 7.7$, respectively; $U=15$, $\left.N_{1}=5, N_{2}=5, P=0.671\right)$.

Out of 256 worker-worker interactions only $6.6 \%$ were aggressive. Aggressive interactions between unrelated workers were significantly more frequent than between

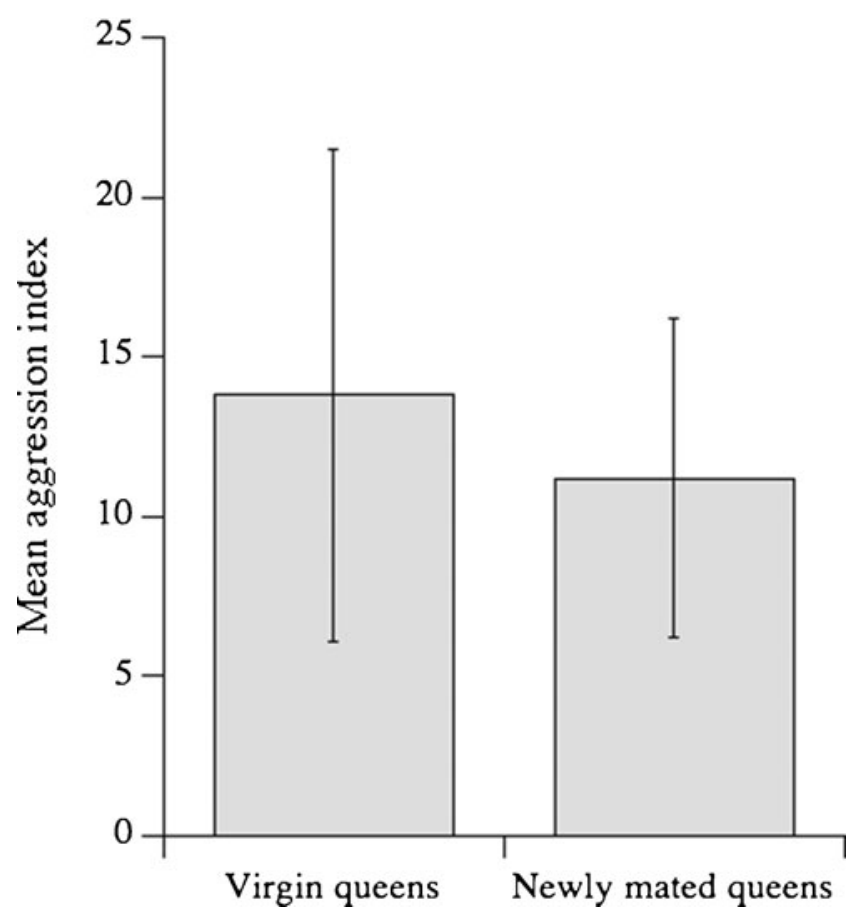

Fig. 2 Intensity of aggression (mean \pm SE) by workers towards VQs and NMQs 
sister workers $\left(12.8 \%\right.$ vs $3.9 \%$ respectively; $\chi^{2}{ }_{1}=4.236$, $\left.N_{1}=3, N_{2}=7, P=0.04\right)$.

Queen chemical profiles as a function of the mating status

A total of 44 hydrocarbons (HCs) were identified in the queens' thoracic extracts (Fig. 3). All but one (pentacosene) were saturated HCs. Two peaks representing a mixture of dimethylalkanes, 3,11-+3,9-+3,7-dimethylnonacosane and 3,9-+3,11-dimethylhentriacontane (peaks 35 and 44 in Fig. 3) were present both in NMQs and VQs, but almost undetectable in workers. The total quantity of HCs extracted from VQs and NMQs cuticles did not differ significantly (Table 2). However, NMQ extracts contained more dimethylalkanes and less linear alkanes than VQs. The amount of monomethylalkanes did not differ significantly according to queens' mating status (Table 2).

Cluster analysis conducted on the relative proportions of the 13 most abundant HCs revealed a clear separation between VQs and NMQs profiles (Fig. 4a). The Bray-Curtis aggregation distance between NMQs and VQs was significantly greater than that among NMQs or among VQs (NMQ-VQ 0.21 vs VQ-VQ 0.12, $Z=5.066, P<0.001$; NMQ-VQ vs NMQ-NMQ $0.09, Z=8.23, P<0.001)$. Principal component analysis confirmed the separation between VQs and NMQs profiles. The first two principal components explained more than $90 \%$ of the total variance (Table 3). VQs projection on the first principal component, which explained $74 \%$ of the total variance, was positive; while all but one NMQ was negative (SM1). NMQs were
Fig. 3 Three gas

chromatograms of cuticular HC profiles of a newly mated queen (a), a virgin queen (b) and a worker (c). Only the major compounds (see the "Methods" section) are denoted on the virgin queen and worker profiles. These compounds are in bold in the legend.

Cholesterol was not included in the analysis
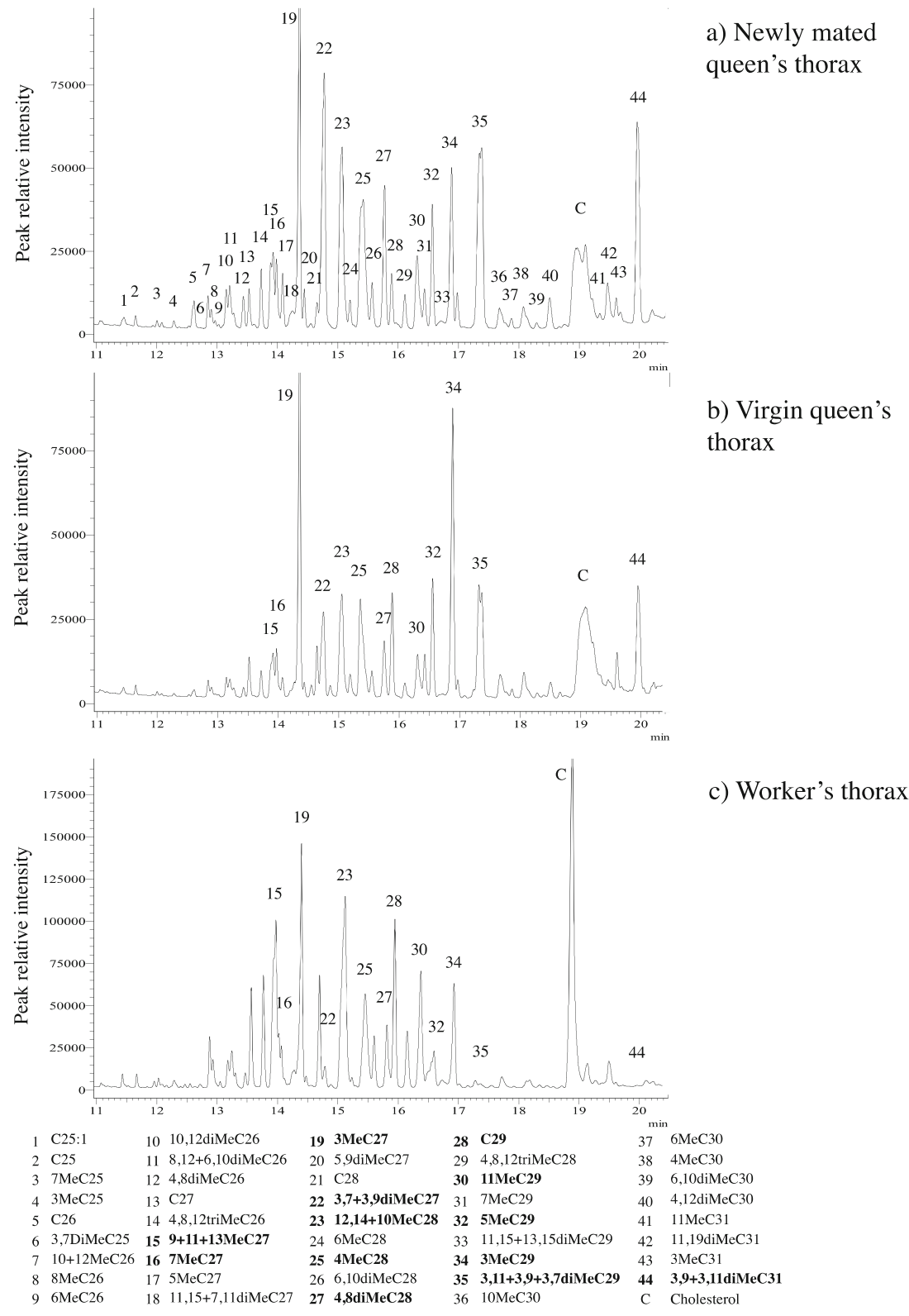
Table 2 Total amount of secretions and of the main chemical classes extracted from the thorax, Dufour gland and poison gland

\begin{tabular}{|c|c|c|c|c|}
\hline Chemical classes & VQs & NMQs & $U$ & $P$ \\
\hline \multicolumn{5}{|l|}{ Thorax HCs } \\
\hline Total secretions & $586.9 \pm 67.8$ & $557.5 \pm 56.4$ & 41 & 0.8601 \\
\hline Linear alkanes & $62.6 \pm 6.3$ & $27.9 \pm 2.7$ & 77 & 0.0006 \\
\hline Monomethylalkanes & $342.4 \pm 42.5$ & $259.4 \pm 26.0$ & 54.5 & 0.1602 \\
\hline Dimethylalkanes & $166.9 \pm 21.7$ & $259.5 \pm 28.5$ & 12 & 0.0083 \\
\hline \multicolumn{5}{|l|}{ Dufour gland } \\
\hline Total secretions & $1201.4 \pm 190.4$ & $448.2 \pm 86.6$ & 73 & 0.0007 \\
\hline Unsaturated HCs & $320.7 \pm 72.3$ & $102.6 \pm 19.3$ & 69 & 0.0042 \\
\hline Linear alkanes & $675.3 \pm 100.0$ & $252.9 \pm 53.3$ & 69 & 0.0065 \\
\hline Monomethylalkanes & $205.1 \pm 26.0$ & $92.2 \pm 17.9$ & 70 & 0.0028 \\
\hline \multicolumn{5}{|l|}{ Poison gland } \\
\hline Total secretions & $763.9 \pm 293.3$ & $114.6 \pm 23.6$ & 6 & 0.0007 \\
\hline Alkaloids & $744.7 \pm 292.2$ & $105.5 \pm 22.0$ & 8 & 0.0042 \\
\hline
\end{tabular}

Lines in bold denote significant differences between VQs and NMQs (Mann-Whitney $U$ test after Holm-Bonferroni correction)

characterized by relatively high concentrations of three mixtures of dimethylalkanes: 3,7-+3,9-dimethypentacosane, 3,11-+3,9-+3,7-dimethylnonacosane and 3,9-+3,11dimethylhentricontane. VQs, in contrast, were characterized by high relative proportions of 3-methylheptadecane, a mixture of 12,14-dimethyloctacosane and 10-methyloctacosane, nonacosane and 3-methylnonacosane (Table 3).

Dufour's gland secretions contained 32 saturated and unsaturated short HCs (between 13 and 19 carbons chain length) accompanied by small amounts of hexadecanal and a still unidentified compound (SM2). VQ Dufour's glands contained more HCs than those of NMQ (Table 2). This difference was true for the three main chemical classes (i.e. unsaturated, monomethylalkanes and dimethylalkanes; Table 2). Queens that had been previously used in the aggression tests possessed a lower amount of secretion in their Dufour's gland than those that had not been used $(273.1 \pm 113.2 \mathrm{ng}$ vs $601.8 \pm 96.8 \mathrm{ng}$ respectively), albeit not statistically significant $(U=6, P=0.126)$.

The relative proportions of the major compounds did not allow differentiation between queens according to their mating status (Fig. 4b). The aggregation distances between NMQs and VQs did not differ from those among NMQs or among VQs (respectively 0.13 vs $0.11, Z=1.147, P=$ $0.247 ; 0.13$ vs $0.13, Z=-0.069, P=0.943)$. This was confirmed by principal component analysis (Table 3, SM1). In particular, NMQs and VQs largely overlapped on the first components, which explained $57.7 \%$ of the total variance.

Nineteen compounds were identified in the poison gland including three alkaloids, $13 \mathrm{HCs}$ and three yet unidentified compounds (SM3). Both the total amount of secretions and the total amount of alkaloids were greater in VQ than in
NMQ poison glands (Table 2). Queens used in the aggression tests possessed a greater amount of secretion than those that had not been used (respectively, $187.6 \pm 22.2 \mathrm{ng}$ vs $53.7 \pm 9.4$ ng $U=30, P=0.004$ ).

Cluster analysis revealed two groups containing mostly NMQs and VQs, respectively (Fig 4c). The distances between NMQs and VQs were significantly higher than among NMQs or among VQs (respectively, 0.23 vs 0.15 , $Z=2.558, P=0.009 ; 0.23$ vs $0.16, Z=4.29, P<0.001)$. Principal component analysis suggested that this difference was mostly due to VQs containing a relatively greater amount of anabaseine than NMQs (SM1; Table 3).

\section{Discussion}

The present study sheds new light on the recognition process that allows the maintenance of monogyny in a social insect featuring colony fission. The findings show that young $A$. senilis queens possess a recognition signal that identifies them as potential challengers for the resident queen irrespective of their mating status. Like mature queens, newly-mated queens clearly inhibit the development of totipotent larvae into future queens, whereas same-age virgin queens tend to have a lower inhibitory capacity. Our chemical analysis suggests the presence of a potential caste and mating status signal, given that the cuticular HCs of mated queens are rich in a series of dimethylalkanes, two of which are almost absent in workers and are present in lesser amounts in virgin queens.

When two distinct groups were placed in an encounter, both the mother queen and workers rapidly attacked the opponent queen, irrespective of her mating status. The aggression was specifically targeted at the queens whereas aggression between workers was low. Moreover, the level of worker aggression did not differ between alien or daughter queens. Thus, aggression of queens was not due to a divergence of nestmate recognition cues between the separated groups (Ichinose et al. 2005). Rather, the young queens were probably recognized as challengers independent of their mating status and fertility. Interestingly, NMQs were always attacked more than they attacked the mother queen. This suggests that aggression was not only driven by mating status but also by dominance, which may be related to age. In many species of ants and other social insects, individuals that challenge the queen's reproductive monopoly are aggressed by workers (Wenselleers and Ratnieks 2004). In the genus Aphaenogaster, such worker policing has been reported in A. cockerelli (Hölldobler and Carlin 1989; Smith et al. 2012) and A. smythiesi (Iwanishi et al. 2003).

From a proximate point of view, several hypotheses may explain overt aggression of infertile $A$. senilis VQs, whereas 
Fig. 4 Dendrogram of chemical distances based on a cuticular HC profile, b Dufour gland profile, and $\mathbf{c}$ poison gland profile between newly mated queens (NMQ) and virgin queens (VQ). The mean profile of 10 workers was added as an out-group (W). Light squares include chemically close individuals and are by a majority VQs. Dark squares include chemically close individuals and are by a majority NMQs
Allocation to the newly mated queen group Allocation to the virgin queen group

a) Thorax $\mathrm{HC}$

b) Dufour gland
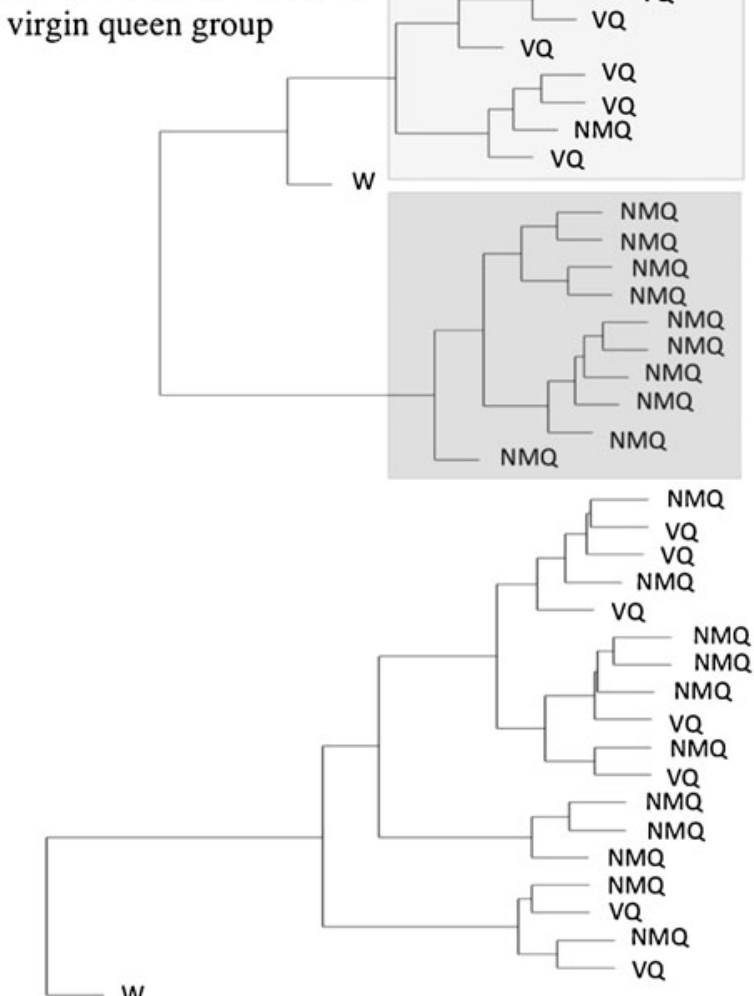

c) Poison gland

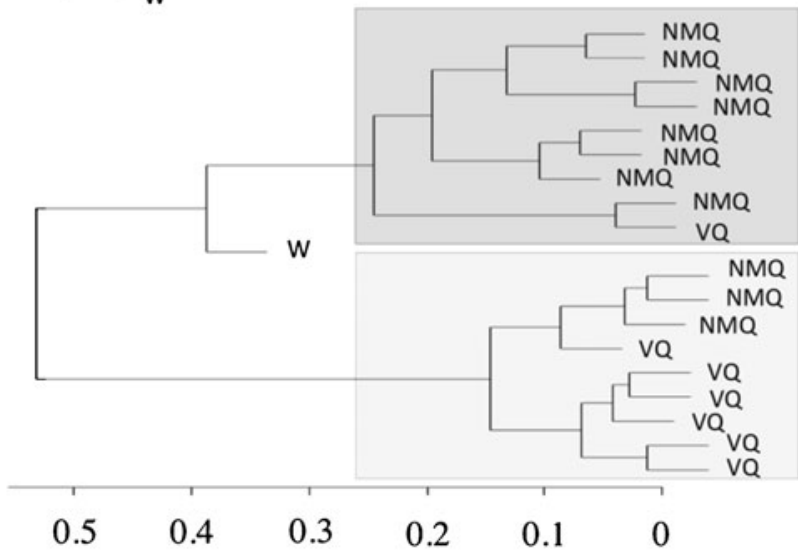

Aggregation distance infertile workers are tolerated, Aggressions could be based on two different signals: a caste signal for queens and a fertility signal for egg-laying workers. Alternatively, the emission of fertility signals, which is correlated to egglaying in workers, could precede ovarian development in the queen caste. From an ultimate perspective, aggression towards daughter queens irrespective of their mating status may be due to the risk of queen supersedure in species with colony fission. Hence, under such a dispersal strategy, the mother queen's reproductive monopoly may be threatened by untimely VQs capable of returning to their nest after mating and taking over reproduction. This possibility is very unlikely in species with independent colony founding in which VQs disperse far from the nest before mating. The strong control on larval development in A. senilis (Boulay et al. 2007) means that untimely queens can be recognized and readily eliminated by workers, unless a fission event occurs soon after emergence. In the monogyne $C$. floricola, which also features colony fission, newly produced queens are transported to the new nest before their emergence, which reduces conflicts with the mother queen; cheater queens that remain in their natal nest are rapidly eliminated by workers (Amor et al. 2011). In the honeybee, the mother queen leaves the nest before the emergence of new queens (Seeley 1985). All new queens but one are eliminated either through queenqueen aggression or through execution by workers. 
Table 3 Percentages (means \pm $\mathrm{SE}$ ) of the major compounds on the thorax, in the Dufour and poison glands for virgin queens (VQs, $n=7$ ) and newly mated queens (NMQs, $n=11$ )
The numbers between parentheses after thoracic HCs refers to compound numbers on Fig. 3. $\mathrm{PC} 1$ and $\mathrm{PC} 2$ indicate the peak scores on principal component analyses

\begin{tabular}{|c|c|c|c|c|}
\hline & VQs & NMQs & & \\
\hline Thorax HCs & & & PC1: $74.9 \%$ & PC2: $11.8 \%$ \\
\hline $9-+11-+13-\mathrm{MeC} 27(15)$ & $3.3 \pm 0.3$ & $2.7 \pm 0.1$ & 0.035 & -0.091 \\
\hline 7-MeC27 (16) & $2.4 \pm 0.2$ & $1.7 \pm 0.1$ & 0.062 & -0.070 \\
\hline 3-MeC27 (19) & $15.1 \pm 0.7$ & $11.6 \pm 0.5$ & 0.376 & 0.057 \\
\hline 3,7-+3,9-diMeC27 (22) & $5.8 \pm 0.5$ & $9.2 \pm 0.4$ & -0.310 & -0.395 \\
\hline 12,14-diMeC28 +10-MeC28 (23) & $8.1 \pm 0.6$ & $6.4 \pm 0.5$ & 0.220 & -0.340 \\
\hline 4-MeC28 (25) & $6.9 \pm 0.5$ & $6.8 \pm 0.3$ & 0.023 & -0.233 \\
\hline 4,8-diMeC28 (27) & $2.9 \pm 0.1$ & $3.8 \pm 0.1$ & -0.088 & -0.124 \\
\hline $\mathrm{C} 29(28)$ & $4.3 \pm 0.4$ & $1.7 \pm 0.1$ & 0.217 & 0.223 \\
\hline $11-\mathrm{MeC} 29(30)$ & $3.0 \pm 0.2$ & $2.6 \pm 0.1$ & 0.053 & -0.081 \\
\hline $5-\mathrm{MeC} 29(32)$ & $3.8 \pm 0.1$ & $3.5 \pm 0.1$ & 0.027 & 0.106 \\
\hline 3-MeC29 (34) & $9.0 \pm 0.6$ & $5.8 \pm 0.3$ & 0.225 & 0.589 \\
\hline 3,11-+3,9- +3,7-diMeC29 (35) & $5.7 \pm 0.8$ & $11.2 \pm 0.6$ & -0.569 & -0.005 \\
\hline 3,9-+3,11-diMeC31 (44) & $2.9 \pm 0.8$ & $7.9 \pm 0.7$ & -0.524 & 0.476 \\
\hline Dufour glands & & & PC1: $57.7 \%$ & PC2: $37.9 \%$ \\
\hline $\mathrm{C} 13$ & $0.9 \pm 0.2$ & $1.7 \pm 0.2$ & 0.015 & -0.088 \\
\hline $\mathrm{C} 14$ & $1.0 \pm 0.1$ & $1.3 \pm 0.1$ & 0.015 & -0.036 \\
\hline $\mathrm{C} 15$ & $45.0 \pm 1.8$ & $41.1 \pm 2.1$ & 0.861 & 0.482 \\
\hline 5-MeC15 & $5.9 \pm 0.6$ & $7.2 \pm 0.5$ & 0.086 & -0.277 \\
\hline 3-MeC15 & $5.4 \pm 0.5$ & $6.7 \pm 0.5$ & 0.039 & -0.278 \\
\hline $\mathrm{C} 16$ & $1.0 \pm 0.1$ & $1.5 \pm 0.1$ & -0.001 & -0.069 \\
\hline 4-MeC16 & $3.0 \pm 0.4$ & $3.0 \pm 0.3$ & -0.098 & 0.050 \\
\hline $\mathrm{C} 17: 2$ & $1.0 \pm 0.2$ & $1.3 \pm 0.1$ & 0.001 & -0.007 \\
\hline $\mathrm{C} 17$ & $7.4 \pm 0.3$ & $6.4 \pm 0.3$ & 0.027 & 0.054 \\
\hline C19: 2 & $3.5 \pm 0.4$ & $3.4 \pm 0.5$ & -0.127 & 0.146 \\
\hline C19: 1 & $19.4 \pm 2.0$ & $15.3 \pm 1.4$ & -0.471 & 0.756 \\
\hline Poison glands & & & PC1: $45.3 \%$ & PC2: $26.6 \%$ \\
\hline $\mathrm{C} 13$ & $0.5 \pm 0.2$ & $1.7 \pm 0.3$ & 0.437 & -0.062 \\
\hline Unknown1 & $0.4 \pm 0.3$ & $1.4 \pm 0.3$ & 0.427 & -0.012 \\
\hline Anabasine & $4.2 \pm 0.5$ & $3.0 \pm 0.8$ & 0.157 & -0.480 \\
\hline Anabaseine & $84.0 \pm 5.5$ & $69.0 \pm 3.5$ & -0.437 & -0.176 \\
\hline Unidentified alkaloid & $7.2 \pm 4.4$ & $18.1 \pm 1.9$ & 0.355 & 0.396 \\
\hline C17: 2 & $1.3 \pm 0.3$ & $0.9 \pm 0.3$ & 0.033 & 0.491 \\
\hline Unknown2 & $0.3 \pm 0.1$ & $0.6 \pm 0.1$ & 0.426 & -0.057 \\
\hline C19: 2 & $1.2 \pm 0.7$ & $0.9 \pm 0.2$ & 0.118 & 0.261 \\
\hline C19: 1 & $0.2 \pm 0.0$ & $1.5 \pm 0.6$ & 0.295 & -0.457 \\
\hline
\end{tabular}

None of the groups containing a NMQ produced a queen whereas 12 of 15 QL groups produced at least one queen. Hence, although they are not completely established and may still be dominated by a mother queen, NMQs rapidly acquire the capacity to inhibit brood development into queens. For the VQs the results are more difficult to interpret given our small sample size. There was no inhibition in three out of seven groups, suggesting an intermediate inhibitory capacity. However, we cannot exclude the possibility that VQs have no inhibitory effect and that the absence of queen production in the remaining four groups resulted from chance. Notwithstanding, we suggest a signal threshold hypothesis for explaining these results, whereby the response to the queen-specific signal is threshold-dependent, being lower for eliciting aggression than for affecting larval development. Hence, the signal levels of some VQs may have been just above the threshold for inhibiting larval determination while others were below, thus allowing larval development into queens. The MQs and the workers could also recognize challenging queens by means of the same pheromones. Their sensitivity threshold would be low in this context and even the lower amount present in VQs would be sufficient to elicit an aggressive response. From the energetic point of view, signal parsimony (relying on 
context-dependent signal threshold to transmit several messages) is more probable than the evolution of various signals.

The most striking chemical difference between NMQs and VQs was the greater amount of dimethylalkanes and lower amount of linear alkanes on the cuticle of the former. Two mixtures of long-chain dimethylalkanes that dominated the NMQs profiles $(3,11-+3,9-+3,7$-dimethylnonacosane and 3,9-+3,11-dimethylhentriacontane) were virtually absent in workers and at intermediate levels in VQs. The relative amounts of these two compounds on NMQs were similar to that observed in a previous study on fieldcollected mature queens (Ruel et al. 2013). Long-chain dimethylalkanes could therefore constitute a reliable signal of caste and mating status in A. senilis. Long-chain dimethylalkanes have been found in higher quantities in egg-layers in at least two other ant species: Pachycondyla inversa (D'Ettorre et al. 2004) and Harpegnathos saltator (Liebig et al. 2000). Ant cuticular HCs are known to vary with a number of factors, including the genetic background (Vander Meer et al. 1998), diet (Liang and Silverman 2000), developmental state (Johnson and Sundström 2012) and fertility (Monnin and Peeters 1997; Liebig et al. 2000; Hannonen et al. 2002; Holman et al. 2010). In the present study, all the queens were from different mother colonies, collected from a natural population so that genetic differences were randomly distributed across treatments. Other factors such as food and queen age were controlled for, suggesting that the observed difference in cuticular HCs was due solely to the physiological changes that accompany mating and egg-laying.

Dufour's and poison gland secretions were more abundant in VQs than in same-age NMQs. The glandular content could serve as a sex pheromone, explaining its reduction in mated queens (Vander Meer et al. 1998; Buschinger 2003). Alternatively, but not exclusively, mated queens could regularly discharge their abdominal glands during contests as well as other marking-related behaviours (Vander Meer and Morel 1995; Bhadra et al. 2007). In two species of ants, Dinoponera quadriceps and A. cockerelli, the gamergates (reproductive workers) and queens, respectively, discharge the content of their Dufour's gland onto challenging workers with developed ovaries (Monnin et al. 2002; Smith et al. 2012). In both species, this elicits strong aggression of the marked individuals by nestmates. Queen and worker Dufour's gland composition was already shown to be significantly different in A. senilis (Boulay et al. 2007) rendering it a likely candidate as the source of caste-related as well as dominance-related signals. However, the absence of a significant difference in the amount of Dufour's gland secretions between queens used in the aggression tests and queens that were not used, refutes the hypothesis that this gland is utilized during contests. Nevertheless, our small sample size limits the statistical power of this comparison. The negligible differences in the composition of the poison gland between VQs and NMQs, exclude the likelihood of it being involved in queen mating status signalling.

To conclude, our study showed that soon after mating the NMQs exhibit chemical and behavioral traits that allow them to establish themselves as reproductive in the absence of a resident mature queen. However, because they were also aggressed by mature queens, they cannot be considered fully established at this stage. Chemical secretions have evolved to signal the presence of a functional queen and generate an adequate response of workers, allowing the maintenance of strict monogyny. Future efforts could be directed at comparing the queen signalling and recognition system between fission-performing species and species in which new queens are readily accepted, leading to polygyny as in many Formica ants. Such studies would surely contribute to our understanding of the evolution of the diversity of social organisations in ants.

Acknowledgments We are grateful to Ana Carvajal for laboratory assistance, and Jessica Pearce, Louise van Oudenhove, Christophe Lejeusne, Michael Jowers and Fernando Amor for their help in the field. We also thank the authority of the Doñana National Park for approving this research. We thank Naomi Paz for editing the English and Liselotte Sundström, Alain Lenoir and Jelle van Zweden for important comments on this manuscript. This work was funded by MICINN and FEDER (projects CGL2009-12472 to RB and CGL2009-09690 to XC). All experiments comply with the current Spanish legislation.

\section{References}

Amor F, Ortega P, Jowers MJ, Cerdá X, Billen J, Lenoir A, Boulay RR (2011) The evolution of worker-queen polymorphism in Cataglyphis ants: interplay between individual- and colony-level selections. Behav Ecol Sociobiol 65:1473-1482

Bhadra A, Iyer PL, Sumana A, Deshpande SA, Ghosh S, Gadagkar R (2007) How do workers of the primitively eusocial wasp Ropalidia marginata detect the presence of their queens? J Theor Biol 246:574-582

Boulay R, Hefetz A, Cerdá X, Devers S, Francke W, Twele R, Lenoir A (2007) Production of sexuals in a fission-performing ant: dual effects of queen pheromones and colony size. Behav Ecol Sociobiol 61:1531-1541

Boulay R, Cerdá X, Fertin A, Ichinose K, Lenoir A (2009) Brood development into sexual females depends on the presence of a queen but on temperature in an ant deispersing by colony fission, Aphaenogaster senilis. Ecol Entomol 34:595-602

Boulay R, Galarza JA, Chéron B, Hefetz A, Lenoir A, Van Oudenhove L, Cerdá X (2010) Intraspecific competition affects population size and resource allocation in an ant dispersing by colony fission. Ecology 91:3312-3321

Bourke AFG, Franks NR (1995) Social Evolution in Ants. Princeton University Press, Princeton

Bourke AFG, Ratnieks FLW (1999) Kin conflict over caste determination in social Hymenoptera. Behav Ecol Sociobiol 46:287-297

Buschinger A (2003) Mating behavior in the ant, Myrmecina graminicola (Myrmicinae). Insectes Soc 50:295-296 
Castella G, Christe P, Chapuisat M (2009) Mating triggers dynamic immune regulations in wood ant queens. J Evol Biol 22:564570

Chéron B, Cronin AL, Doums C, Fédérici P, Haussy C, Tirard C, Monnin T (2011) Unequal resource allocation among colonies produced by fission in the ant Cataglyphis cursor. Ecology 92:1448-1458

Cronin AL, Molet M, Doums C, Monnin T, Peeters C (2013) Recurrent evolution of dependent colony foundation across eusocial insects. Ann Rev Entomol 58:37-65

Crozier RH, Pamilo P (1996) Evolution of social insect colonies. Sex allocation and kin-selection. Oxford University Press, Oxford

D'Ettorre P, Heinze E, Schulz C, Francke W, Ayasse M (2004) Does she smell like a queen? Chemoreception of a cuticular hydrocarbon signal in the ant Pachycondyla inversa. J Exp Biol 207:1085-1091

Galarza JA, Jovani R, Cerdá X, Rico C, Barroso Á, Boulay R (2012) Frequent colony relocations do not result in effective dispersal in the gypsy ant Aphaenogaster senilis. Oikos 121:605-613

Gotwald WH (1995) Army ants: the biology of social predation. Cornell University Press, Ithaca

Hamilton WD (1964) The genetical evolution of social behaviour I. J Theor Biol 7:1-16

Hannonen M, Sledge MF, Turillazzi S, Sundström L (2002) Queen reproduction, chemical signalling and worker behaviour in polygyne colonies of the ant Formica fusca. Anim Behav 64:477-485

Hefetz A (2007) The evolution of hydrocarbon pheromone parsimony in ants (Hymenoptera: Formicidae) - interplay of colony odor uniformity and odor idiosyncrasy. A review. Myrmecol News 10:59-66

Hölldobler B, Carlin NF (1989) Colony founding, queen control and worker reproduction in the ant Aphaenogaster (=Novomessor) cockerelli (Hymenoptera: Formicidae). Psyche 96:131-151

Hölldobler B, Wilson EO (2009) The Superorganism: The Beauty, Elegance, and Strangeness of Insect Societies Norton \& Co. Incorporated, New York

Holman L, Jørgensen CG, Nielsen J, D'Ettorre P (2010) Identification of an ant queen pheromone regulating worker sterility. Proc R Soc Lond 277:3793-3800

Hora RR, Ionescu-Hirsh A, Simon T, Delabie J, Robert J, Fresneau D, Hefetz A (2008) Postmating changes in cuticular chemistry and visual appearance in Ectatomma tuberculatum queens (Formicidae: Ectatomminae). Naturwissenschaften 95:55-60

Ichinose K, Cerdá X, Christidès J-P, Lenoir A (2005) Detecting nestmate recognition patterns in the fission-performing ant Aphaenogaster senilis: a comparison of Different Indices. J Insect Behav 18:633-650

Iwanishi S, Hasegawa E, Ohkawara K (2003) Worker oviposition and policing behaviour in the myrmicine ant Aphaenogaster smythiesi japonica. Forel Anim Behav 66:513-519

Johnson CA, Sundström L (2012) Cuticular chemistry of two social forms in a facultatively polygyne ant (Hymenoptera: Formicidae: Formica truncorum). Ann Zool Fennici 49:1-17

Keller L (1991) Queen number, mode of colony founding, and queen reproductive success in ants (Hymenoptera, Formicidae). Ethol Ecol Evol 3:307-316

Klobuchar EA, Deslippe RJ (2002) A queen pheromone induces workers to kill sexual larvae in colonies of the red imported fire ant (Solenopsis invicta). Naturwissenschaften 89:302-304

Kocher SD, Richard FJ, Tarpy DR, Grozinger CM (2008) Genomic analysis of post-mating changes in the honey bee queen (Apis mellifera). BMC Genomics 9:232

Kocher SD, Richard FJ, Tarpy DR, Grozinger CM (2009) Queen reproductive state modulates pheromone production and queenworker interactions in honeybees. Behav Ecol 20:1007-1014
Liautard C, Keller L (2001) Restricted effective queen dispersal at a microgeographic scale in polygynous populations of the ant Formica exsecta. Evolution 55:2484-2492

Liang D, Silverman J (2000) "You are what you eat": Diet modifies cuticular hydrocarbons and nestmate recognition in the Argentine ant. Linepithema humile Naturwissenschaften $87: 412-416$

Leniaud L, Darras H, Boulay R, Aron S (2012) Social hybridogenesis in the clonal ant Cataglyphis hispanica. Cur Biol 22:11881193

Liebig J, Peeters C, Oldham NJ, Markstadter C, Hölldobler B (2000) Are variations in cuticular hydrocarbons of queens and workers a reliable signal of fertility in the ant Harpegnathos saltator? Proc Natl Acad Sci USA 97:4124-4131

Monnin T, Peeters C (1997) Cannibalism of subordinates' eggs in the monogynous queenless ant Dinoponera quadriceps. Naturwissenschaften 84:499-502

Monnin T, Ratnieks FLW, Jones GR, Beard R (2002) Pretender punishment induced by chemical signalling in a queenless ant. Nature 419:61-65

Nonacs P, Tobin JE (1992) Selfish larvae: Development and the evolution of parasitic behavior in the Hymenoptera. Soc Study Evol 46:1605-1620

Pamilo P (1991) Evolution of colony characteristics in social insects II. Number of reproductive individuals. Am Nat 138:412-433

Pearcy M, Aron S, Doums C, Keller L (2004) Conditional use of sex and parthenogenesis for worker and queen production in ants. Science 306:1780-1783

Quinn G, Keough M (2002) Experimental design and data analysis Cambridge University Press, Cambridge

Ross K, Matthews G (1991) The social biology of wasps. Comstock Publishing Associates, Ithaca and London

Ruel C, Cerdá X, Boulay R (2012) Behaviour-mediated group size effect constrains reproductive decision in a social insect. Anim Behav 84:853-860

Ruel C, Lenoir A, Cerdá X, Boulay R (2013) Surface lipids of queenlaid eggs do not regulate queen production in a fission-performing ant. Naturwissenschaften 100:91-100

Seeley TD (1985) Honeybee ecology: a study of adaptation in social life. Princeton University Press, Princeton

Smith AA, Hölldober B, Liebig J (2009) Cuticular hydrocarbons reliably identify cheaters and allow enforcement of altruism in a social insect. Curr Biol 19:78-81

Smith AA, Hölldobler B, Liebig J (2012) Queen-specific signals and worker punishment in the ant Aphaenogaster cockerelli: the role of the Dufour's gland. Anim Behav 83:587-593

Vander Meer RK, Morel L (1995) Ant queens deposit pheromones and antimicrobial agents on eggs. Naturwissenschaften 82: 93-95

Vander Meer RK, Glancey BM, Lofgren CS, Glover A, Tumlinson JH, Rocca J (1980) The poison sac of red imported fire ant queens source of a pheromone attractant (Hymenopetra, Formicidae). Ann Entomol Soc Am 73:609-612

Vander Meer RK, Breed MD, Espelie KE, Winston ML (1998) Pheromone communication in social insects: ants, wasps, bees, and termites. Westview Press, Boulder, CO

Vargo EL (1997) Poison gland of queen fire ants (Solenopsis invicta) is the source of a primer pheromone. Naturwissenschaften 84:507510

Vargo EL, Husley CD (2000) Multiple glandular origins of queen pheromones in the fire ant Solenopsis invicta. J Insect Physiol 46:1151-1159

Wenseleers T, Ratnieks FLW (2004) Tragedy of the commons in Melipona bees. Proc R Soc of Lond B 271:S310-S312 